\title{
Economic Contributions of Jima Ganati Farmers' Cooperative Union to Farmers: The Case of Maize Producer Farmers
}

\author{
Firdisa Birru Goshu \\ Lecturer of Economics at Wollega University, Ethiopia
}

\begin{abstract}
This article investigates the impact evaluation of Jima Ganati farmers' cooperative union intervention in economic activities which is measured in terms of income and productivity as the best means to improve the living standard of farmers' household.. For this, cross-sectional data were collected from 280 households purposively selected from five kebeles consisting of 204 member farmers and 76 non-member farmers. The analytical procedure has involved two stages: in the first stage, descriptive analyses were used to detect existence of difference in various outcome indicators between member farmers and non-member farmers. In the second stage, I applied a semi-parametric impact evaluation method of propensity score matching with some matching algorithms to estimate the impact of the intervention on various impact indicators. Combined use of these alternative estimation techniques has enabled us to arrive at consistent results. Our results show that member farmers scored statistically significant higher maize crop income test score than non-member farmers and they are also identified with statistically significant higher total productivity. Although the crop income and productivity test scores show significant changes, some constraints were identified in the economic contributions of the cooperative union to farmers and these include: high turnover of the union mangers, lack of skill in cooperative development, rent seeking behavior of the cooperative leaders, lack of transparency, Accordingly, a number of recommendations are suggested.
\end{abstract}

Keywords: Propensity score matching; economic contribution; maize income; productivity; impact; cooperative union.

DOI: $10.7176 /$ JPID/49-01

Publication date: April $30^{\text {th }} 2019$

\section{1. background of the study}

Cooperatives can be significant economic players that contribute to sustained growth processes. The top 300 global co-operatives have a combined turnover of US \$1.1 trillion. Cooperatives employ over 100 million people (more than multinational corporations) and contribute to increased agricultural productivity, expanded access to financial services and critical utilities such as electricity. Cooperatives can make a significant contribution to GDP (DFID, 2010). In the sector of agriculture, cooperatives contribute to food production and distribution, and in supporting long-term food security. They also help in tackling rural poverty by increasing the productivity and income of smallholder farmers by helping them collectively negotiate better prices for seeds, fertilizer, transport and storage. They further help farmers expand market access and capture more of the value chain by getting involved in agro-processing activities (Woldu, 2007). Farmer groups can help farmers move out of poverty, and cooperatives are one form that these groups can take and the cooperatives are often the main channel through which smallholders can access fair-trade Imoisili, (Belay, B., 2016).

The overall development strategy of Ethiopia is based on the development of a strong free market economic system. Policies towards the development of the agricultural sector and its role in the Ethiopian economy as a whole are guided by the strategy of Agricultural Development Led Industrialization (ADLI), which has been put forward by the Government of Ethiopia in 2001. ADLI has an aim to bring about a structural transformation in the productivity of the peasant agriculture and to streamline and reconstruct the manufacturing (Industrial) sector, so that it makes extensive use of the country's natural and labor resources (MoFED, 2017).

Most of the agricultural production in Ethiopia is undertaken by small scale producers scattered all over the country, engaged in different agricultural enterprises without specialization, and with limited marketable surplus. The weak performance of the agricultural markets (both input and output markets) in Ethiopia has been presented in various studies as a major impediment to growth in the agricultural sector and the overall economy (Alema, 2008).With an inefficient marketing system, the surplus resulting from increased production benefits neither the farmers nor the country. This is particularly important as the country is following a policy of agriculture -led industrialization and economic development where the agricultural sector is expected to produce surplus that can move to the other sectors of the economy (Eleni et al., 2004). Although cooperatives are considered as an appropriate tool of rural development they are facing critical problems, which retain them from their positive role. Some of the constraints of farmers' cooperatives are: failure to benefit the end users (farmers),lack of market information and poor marketing services, inadequate qualified personnel, low entrepreneurship skill, lack of financial resources, rent seeking behavior of the cooperative leaders, poor members' participation in the different cooperative activities and services (Dereje, A., 2015). 
The studies reviewed so far have not discussed the role of cooperative union in Jima Ganati District. Thus, the present study is unique and it makes an attempt to bring forth the role of cooperative union in economic contribution to farmers in the study area. Therefore, this research is carried out to assess the economic contributions of Jima Ganati Farmers' Cooperative Union to farmers and help bridge the research gap on the issue and identify those factors influencing the economic contributions of the union. The general objective of the paper is to assess the economic contributions of Jima Ganati farmers' cooperative union to maize producer farmers.

The study also has the following specific objectives. It tried to :

- assess the economic contributions of Jima Ganati farmers' cooperative union to farmers measured in terms of income and productivity

- assess the role of cooperative union in price stabilization

- analyse the determinants of the farmers' cooperative union in economic contributions to maize producer farmers

\section{Conceptual Framework}

For the effective functioning of the cooperative activities, members' participation is a decisive pillar of the cooperative. Members who participate are aware of the importance of the cooperative societies socially and economically. They can make themselves aware of the problems and have the willingness to contribute to the progress of the cooperatives and their membership ensures member participation in the business and managerial affairs of the cooperatives (Duguma, A., Feyisa, T., 2017). In the study, the concept of participation lays the involvement of members in patronizing the agricultural input and output marketing carried out by cooperatives. Therefore, factors that will contribute to the eventual economic contributions of the union to farmers are presented as follows. The below figure shows conceptual framework of the study through which the cooperative intervention achieves the objectives set (Taye, W., 2014).

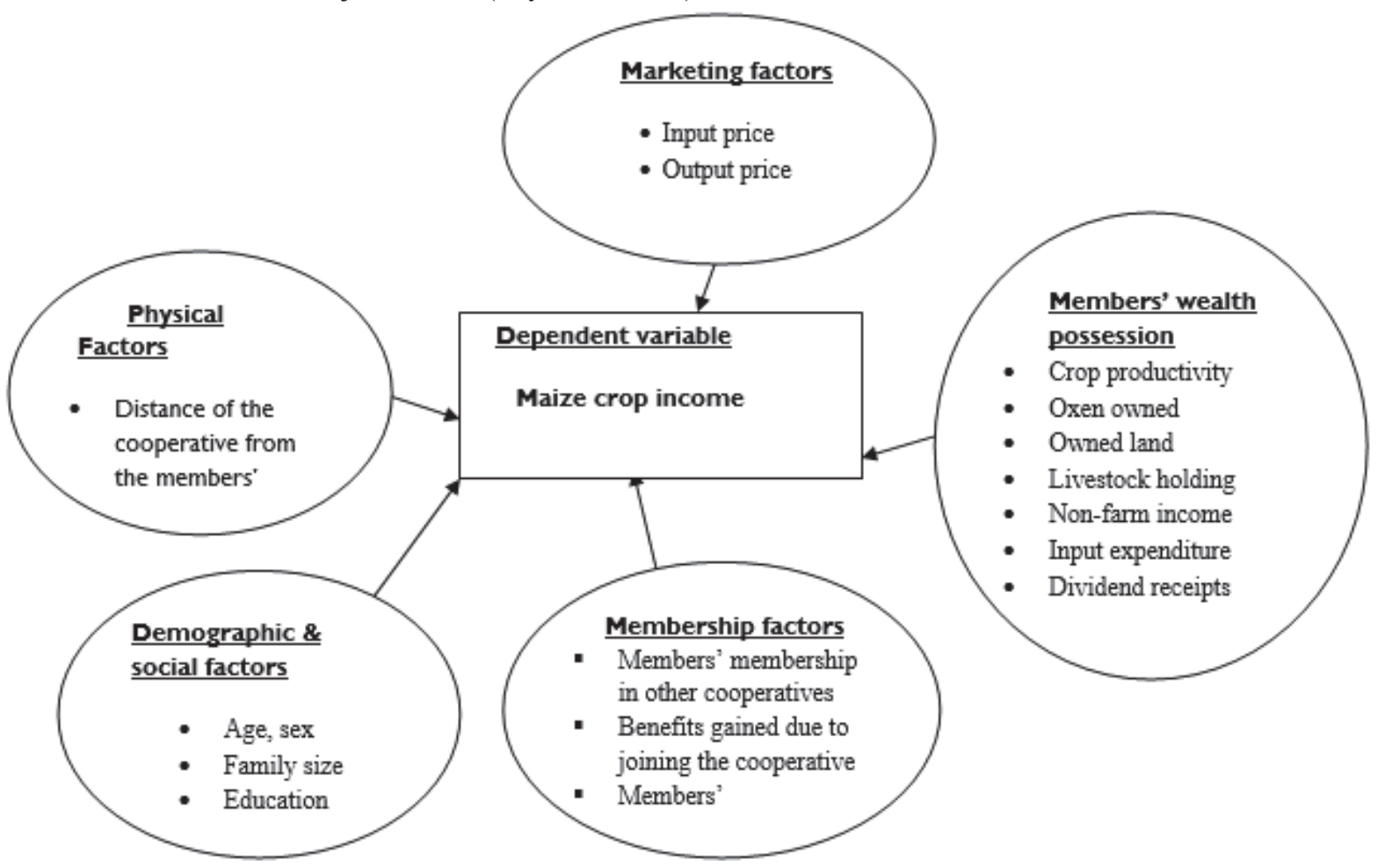

\section{Hypothesis}

In line with the research (empirical) objectives, the following hypotheses had been assessed and analyzed;

$\mathbf{H}_{\mathbf{0}}$ : Yearly maize crop income of cooperative member farmers is insignificantly below those of non-member farmers.

Ho: Yearly crop productivity (maize) of cooperative member farmers is significantly above those of nonmember farmers.

Ho: Yearly expenditure on agriculture of member farmers exceeds those of non- members 


\section{Related Literature}

The International Cooperatives Alliance (ICA) 1995 defines a cooperative as "An autonomous association of persons united voluntarily to meet their common economic, social and cultural needs and aspirations through a jointly owned and democratically-controlled enterprise." Center for Cooperative (2002) also defined cooperative as "a private business organization that is owned and controlled by the people who use its products, supplies or services." Although cooperatives vary in type and membership size, all were formed to meet the specific objectives of members, and are structured to adapt to members' changing needs (Woldu 2007) considered cooperative as a democratically controlled business i.e. it is owned and controlled by the members. It also gives benefit to the members.

A well-functioning agricultural cooperative is an important element to materialize agricultural development strategy It could enable farmers' to get a fair proportion of consumers' price, enhance farm income and, consequently, allow the process of agricultural intensification to intensify further with a positive impact on poverty reduction (Dula, S., 2016 ). Bedasa (2018), applied the model to assess the impact of Integrated Food Security Program in Sidama district of SNNP region. The study found that the program has increased participating households' calorie intake by 45\% (i.e., 799 calories) compared to that of nonparticipating households. In assessing the impact of the Productive Safety Net Program (PSNP) in Ethiopia on livestock and tree holdings of rural households, Andersson et al. (2009), have applied PSM model. They found that there was no indication that participation in PSNP leads households to disinvest in livestock or trees. In fact, the number of trees increased for households that participated in the program.

In analyzing the impact of social protection on food security and coping mechanisms in Ethiopia's productive safety nets program, Gilligan et al. (2008), used PSM methods and they found that participation in the public works component of the PSNP (defined as receipt of at least 100 Birr) in payments over the first five months has modest effects. It improves food security by 0.40 months and increases growth in livestock holdings by 0.28 Tropical Livestock Units (TLU). It leads to an increase of 4.4 percentage points in the likelihood that a household is forced to make a distress asset sale. Bernard et al. (2010) applied PSM in assessing the impact of cooperatives on smallholders' commercialization of staple crops using the output price offered and proportion of output sold as indicators. They found that cooperatives deliver, on average, seven percent price premium for their members' output, relative to what these farmers would have received had they decided to market their output individually.

In Ethiopia, according to (Bezabih, 2009) data obtained from FCA indicates that as of 2007, there were 23,000 employees of primary cooperatives in Ethiopia. In the same year the employees of cooperative unions were estimated at 838 , making the total number of employees working in cooperatives to be 23,858 . According to FCA (2008a), cooperatives also support the self employment of 115,079 members. Every union has a manager and between ten to 35 permanent employees with different fields of specializations. If we assume the average number of permanent employees per union to be 20, then the total number of permanent employees would be 2,860 , which is higher than the 838 estimate by the FCA.

\section{METHODS AND MATERIALS}

\subsection{Description of the study area}

The Oromia national regional state lies in the central part of the country with larger protrusions towards the south and west directions. It has an area of $363,375 \mathrm{~km} 2$ (BOFED, 2017) accounting for about 34.3 percent of the total area of the Federal Democratic Republic of Ethiopia. The region is administratively classified into 18 zones, 304 districts and 6349 rural and 540 urban kebeles. The population of the region is more than 50 million, of which the economically active population (15-64) accounted for 50.2 percent and the total average household size was estimated at 4.8 people (CSA, 2007). The estimated livestock population was 41.6 million. The total estimated arable land was 30.7 percent of the region total area and average land holding per farmer household was about 4.3 ha. Maize, Teff, wheat, barley, sorghum, bean, etc. are some of the widely cultivated crops in the region (BOFED, 2010). A report obtained from Oromia cooperative promotion Agency in 2013 indicates that there are 124 different types of secondary cooperative societies (unions) in the region, of which 68.5 percent are agricultural multipurpose cooperatives which deal with the input and output marketing. The remaining 31.5 percent cooperative unions comprise of saving and credit, consumers, irrigation and other type of cooperative societies.

Jimma Genneti is one of the 10 Districts found in Horo Guduru Wollega Zone and is located to the southern part of the zone, at $27 \mathrm{~km}$ to the south of Shambu town, capital city of the zone and $314 \mathrm{~km}$ from Addis Ababa, capital city of the country. It is sub-divided in to 12 farmer associations and 2 towns for its administrative purpose. The Geographically the district is bordered by; In the south by Horo Guduru Zone, In south west by East welega Zone, In the West by Horo district, In the North west by Horo and In the east by Guduru district.In the east south by Jimma Rare district. 


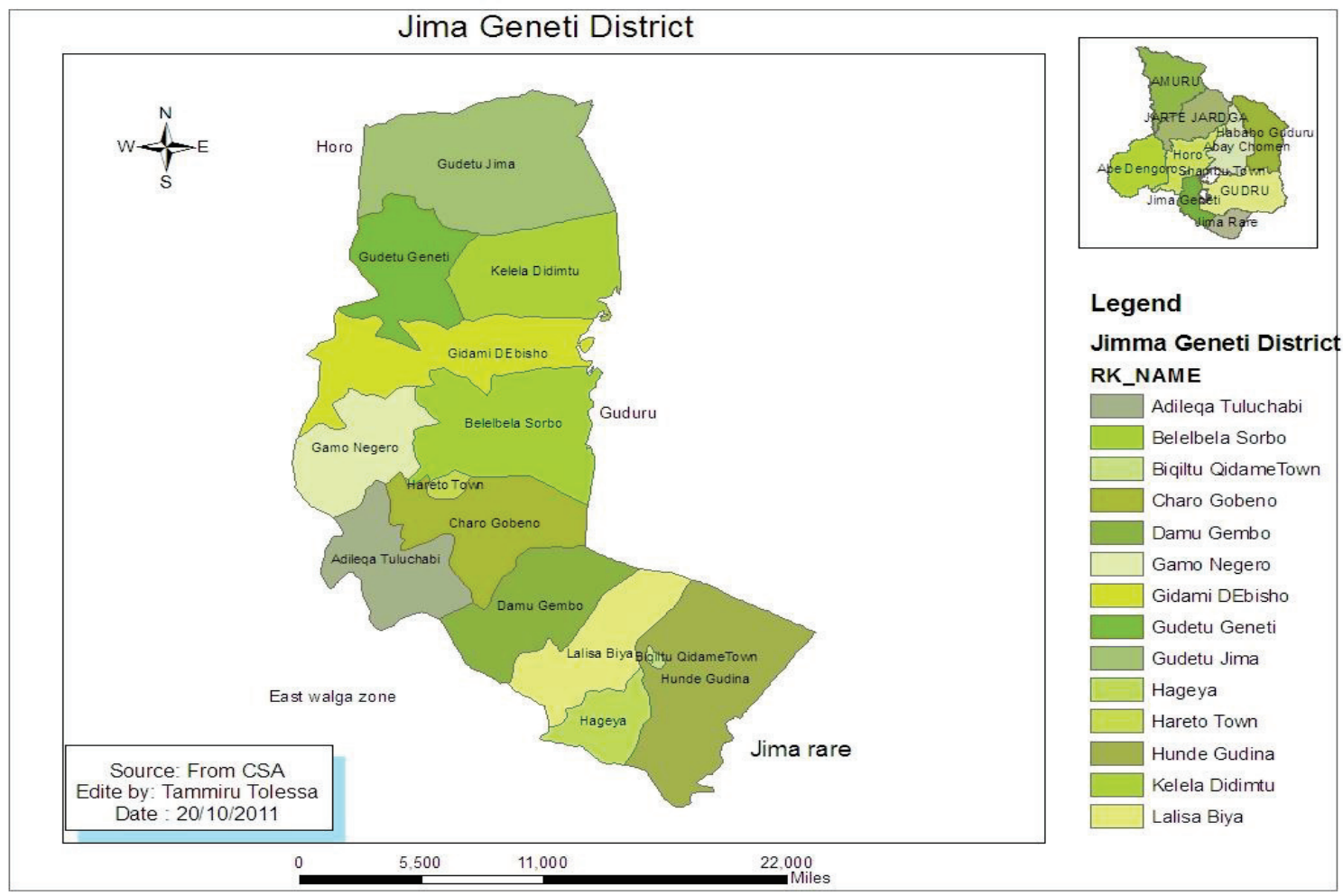

The altitude range of the district is from $1900 \mathrm{~m}$ to $3000 \mathrm{~m}$ above sea level. The District is situated at an altitude $1900 \mathrm{~m}$ above sea level and the dominant climatic condition is sub-tropical climate type. The mean annual rain fall of the District is about $1600 \mathrm{~mm}-2000 \mathrm{~mm}$ and has a mean annual temperature between $15^{\circ} \mathrm{c}$ and $20^{\circ} \mathrm{c}$ (degree Celsius). Estimated total population in 2016 is 91,078 projected based on 2015 census. From this about 80,331 of the district's population are settled in rural and only 10,747 live in urban areas (CSA projection, 2015).

\subsection{Study period and Study designs}

The study was conducted from June to September 30, 2018. A community based cross sectional study design was employed. Semi-structured interview and questionnaires were used to collect information in the area of socio-demographic, and others.

\subsection{Source of Population}

All farmers sampled for this purpose in Jima Ganati who are members and non-members of the cooperative Union. The information collected includes both primary data from sample households and secondary data from the respective offices.

\subsection{Sample Size and Sampling Techniques}

\subsubsection{Sample Size Determination}

The population under study area is known and the researcher has drawn conclusions on the basis of a sample and, therefore sample size determination is an important element in any survey research. In practice, one of the most popular approaches to sample size determination formula (Kothari, 2004) employed was expressed as follows;

$$
\left.\mathrm{n}=\frac{\underline{z}^{2}}{e^{2}} \mathrm{pq}_{N} \underline{N}-1\right)+z^{2}(p q)
$$

Where, $\mathrm{n}=$ Sample size

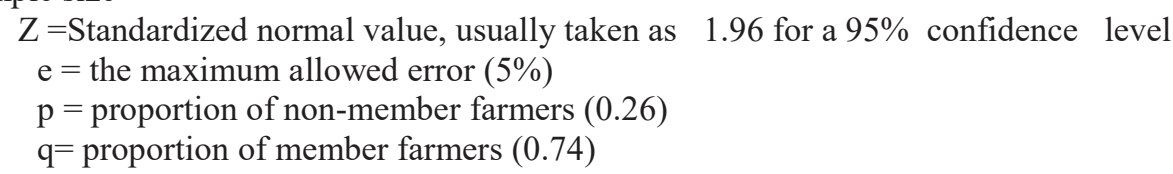

$\mathrm{N}=$ Total target population (6400)

Based on this sample size determination formula, the true population of 6400 is $95 \%$ confident level. Also, 
it is calculated that the proportions of the cooperative member farmers and non-member farmers are about $74 \%$ and $26 \%$ respectively. By employing the above stated formula, the size of the sample was 280 and a structured questionnaire was administered to 280 sampled households of members and non-member households in the selected Kebeles. In doing so, training was given to three diploma holders enumerators on the prepared questionnaire.

\subsubsection{Sampling Techniques}

To meet the set aims of the study, four staged sampling techniques were adopted to collect the required primary data. The first stage involved purposively selection of Horo Guduru Wollega zone, the second stage involved purposively selection of Jima Ganati district from ten districts, the third stage involved purposively selection of five Kebeles from rural Kebeles and finally (fourth stage) probability proportional to the size was employed to select 204 households from the member farmers and 76 households from non-member farmers which totally constitute the size of the sample to 280 out of almost 6400 target population.

Table 3.3 Sample size by Kebele

\begin{tabular}{|l|c|c|c|c|c|c|c|}
\hline \multirow{2}{*}{ Sample Kebeles } & \multicolumn{3}{|c|}{ Member farmers } & \multicolumn{3}{c|}{ Non-member farmers } & \multicolumn{2}{c|}{$\begin{array}{c}\text { Total } \\
\text { n(Sample } \\
\text { size) }\end{array}$} \\
\cline { 2 - 8 } & $\begin{array}{c}\text { Number of } \\
\text { HHs }\end{array}$ & $\%$ & $\mathrm{n}$ & $\begin{array}{c}\text { Number of } \\
\text { HHs }\end{array}$ & $\%$ & $\mathrm{n}$ & 97 \\
\hline Gudetu Jimma & 1871 & 39.51 & 81 & 359 & 21.57 & 16 & 97 \\
\hline Balbala Sorgo & 1257 & 26.54 & 54 & 472 & 28.36 & 22 & 76 \\
\hline Lalisa Biya & 570 & 12.03 & 24 & 402 & 24.15 & 18 & 42 \\
\hline Gudetu Ganati & 616 & 13.01 & 27 & 244 & 14.66 & 11 & 38 \\
\hline Gamo Negero & 422 & 8.91 & 18 & 187 & 11.26 & 9 & 27 \\
\hline Total & $\mathbf{4 7 3 6}$ & $\mathbf{1 0 0}$ & $\mathbf{2 0 4}$ & $\mathbf{1 6 6 4}$ & $\mathbf{1 0 0}$ & $\mathbf{7 6}$ & $\mathbf{2 8 0}$ \\
\hline
\end{tabular}

Source: Own Survey, 2018

\subsection{Methods of Data Analysis}

Descriptive statistics such as mean, standard deviation, percentages, graphs and cross tabulations are used in analyzing the data.

\subsubsection{Propensity score matching}

One of the critical problems in non experimental methods is the presence of selection bias which could arise mainly from nonrandom location of the project and the nonrandom selection of participant households that makes evaluation problematic (Heckman et al., 1998). According to Bernard et al. (2010), there are three potential source of bias. The first one is that participant households may significantly differ from nonparticipants in community as well as household level due to observable characteristics((such as geographic remoteness, or a household's physical and human capital stock) that may have a direct effect on outcome of interest. Secondly, the difference arises due to unobservable characteristic. As Ravallion (2005), argues contamination of the control group can be hard to avoid due to the responses of markets and governments. For instance, Bernard et al. (2010), minimize the effect of spillover effect on comparison group by comparing cooperative members to similar households located in other kebeles where there are no cooperative. In order to achieve objectives, PSM nonexperimental method was employed to know the impact of development interventions made by cooperative union on different outcome variables. It is chosen among other non experimental methods because it does not require baseline data, the treatment assignment is not random and considered as second-best alternative to experimental design in minimizing selection biases mentioned above (Baker, 2000). In this case to estimate the effect of member farmers' participation in the cooperative economic activities on a given outcome $(\mathbf{Y})$ is specified as:

\section{Ti=Yi $(\mathbf{D i}=1)-\mathrm{Yi}(\mathrm{Di}=0)$}

Where $\boldsymbol{T} \boldsymbol{i}$ treatment effect (effect due to participation in the cooperative services/economic activities), $\boldsymbol{Y} \boldsymbol{i}$ is the outcome on household members $\boldsymbol{D i}$ is whether household $\boldsymbol{i}$ has got the treatment or not (i.e., whether a household participated in the services/economic activities facilitated by the cooperative or not).

However, one should notice that $\mathrm{Yi}(\mathrm{Di}=1)$ and $\mathrm{Yi}(\mathrm{Di}=0)$ cannot be observed for the same household at the same time. Depending on the position of the household in the treatment(participation in economic activities), either $\mathrm{Yi}(\mathrm{Di}=1)$ or $\mathrm{Yi}(\mathrm{Di}=0)$ is unobserved outcome (called counterfactual outcome).Due to this fact, estimating individual treatment effect $\mathrm{Ti}$ is not possible and one has to shift to estimate the average treatment effects of the population than the individual one. Two treatment effects are most frequently estimated in empirical studies. The first one is the (population) Average Treatment Effect (ATE), which is simply the difference of the expected outcomes after participation and non-participation:

This measurement answers the question what would be the effect if households in the population will be randomly assigned to treatment. But, Heckman et al. (1997), note that this estimate might not be of importance 
to policy makers because it includes the effect for which the economic activity is never intended.

Therefore, the most important evaluation parameter is the so called Average Treatment Effect on the Treated (ATT), which concentrates solely on the effects on those for whom the cooperatives are actually organized. In the sense that this parameter focuses directly on those households who are member farmers, it determines the realized impact from the cooperative and helping to decide whether the cooperative is successful or not. It is given by:

$\mathbf{T}_{\mathrm{ATT}}=\mathrm{E}(T \mid D=1)=\mathrm{E}\left(\mathrm{Y}_{1} \mid \mathrm{D}=\mathbf{1}\right)-\mathbf{E}\left(\mathrm{Y}_{\mathbf{0}} \mid \mathrm{D}=\mathbf{1}\right)$

This answers the question of how much do members participate in the cooperative benefit compared to what they would have experienced without participating in the cooperatives. Data on $E\left(Y_{1} \mid D=1\right)$ are available from the cooperative participants. An evaluator's classic problem is to find $E\left(Y_{0} \mid D=1\right)$, so the difference between $E$ $\left(\mathrm{Y}_{1} \mid \mathrm{D}=1\right)-\mathrm{E}\left(\mathrm{Y}_{0} \mid \mathrm{D}=1\right)$ cannot be observed for the same household. Due to this problem, one has to choose a proper substitute for it in order to estimate ATT.

The possible solution for this is to use the mean outcome of the comparison individuals, $E\left(Y_{0} \mid D=0\right)$ as a substitute to the counterfactual mean for those being treated, $\mathrm{E}\left(\mathrm{Y}_{0} \mid \mathrm{D}=1\right)$ after correcting the difference between treated and untreated households arising from selection effect. Thus, by rearranging, and subtracting $E\left(Y_{0} \mid \mathrm{D}=0\right)$ from both sides of equation (3), one can get the following specification for ATT.

$\mathbf{E}\left(\mathbf{Y}_{\mathbf{1}} \mid \mathbf{D}=\mathbf{1}\right)-\mathbf{E}\left(\mathbf{Y}_{\mathbf{0}} \mid \mathbf{D}=\mathbf{0}\right)=\mathbf{T}_{\mathrm{ATT}}+\mathbf{E}\left(\mathbf{Y}_{\mathbf{0}} \mid \mathbf{D}=\mathbf{1}\right)-\mathbf{E}\left(\mathbf{Y}_{\mathbf{0}} \mid \mathbf{D}=\mathbf{0}\right)$

Both terms in the left hand side are observables and ATT can be identified, if and only if $\mathrm{E}\left(\mathrm{Y}_{0} \mid \mathrm{D}=1\right)-\mathrm{E}$ $\left(\mathrm{Y}_{0} \mid \mathrm{D}=0\right)=0$ i.e., when there is no self-selection bias. This condition can be ensured only in social experiments where treatments are assigned to units randomly (i.e., when there is no self-selection bias). In non-experimental studies one has to introduce some identifying assumptions to solve the selection problem. The following two assumptions were suggested to solve the selection problem (Caliendo and Kopeinig, 2008)

Firstly we need to maintain conditional independence assumption (CIA) stated as;

$\mathbf{Y}_{\mathbf{0}} \perp \mathbf{D} \mid \mathbf{X}$

Where $\perp$ indicates independence, $\mathrm{X}$ is a set of observable characteristics, $\mathrm{Y}_{0}$ nonparticipants. Given a set of observable covariates $(\mathrm{X})$ which are not affected by treatment (in our case, participating in cooperative services), potential outcomes (input use intensity, level of productivity, income, etc) are independent of treatment assignment (independent of how the participation decision is made by the household). This assumption implies that the selection is solely based on observable characteristics (X), and variables that influence treatment assignment (participation decision is made by the household) and potential outcomes productivity level, income) are simultaneously observed (Bryson et al., 2002; Caliendo and Kopeinig, 2008). Hence, after adjusting for observable differences, the mean of the potential outcome is the same for $\mathrm{D}=1$ and $\mathrm{D}=0$ and $\mathrm{E}(\mathrm{Y} 0 \mid \mathrm{D}=1, \mathrm{X})=$ $\mathrm{E}(\mathrm{Yo} \mid \mathrm{D}=0, \mathrm{X})$

The second requirement is common support region assumption where the balancing score has positive density for both treatment and comparison units. This assumption rules out perfect predictability of $\mathrm{D}$ given $\mathrm{X}$

That is: $\mathbf{0}<\operatorname{Pr}(\mathbf{D}=\mathbf{1} \mid \mathbf{X})<\mathbf{1}$

This assumption improves the quality of the matches as it excludes the tails of the distribution of (X), though this is done at the cost that sample may be considerably reduced. Yet, nonparametric matching methods can only be meaningfully applied over regions of overlapping support .No matches can be formed to estimate the parameters when there is no overlap between the treatment and comparison groups. It also guarantees an individual with identical observable characteristics to have a positive probability of belonging both to the participants and control group (Rosenbaum and Rubin, 2005). Given the above assumptions, the PSM estimator of ATT can be written as:

$\mathrm{T}_{\mathrm{ATT}}=\mathrm{E}\left(\mathrm{Y}_{1}-\mathrm{Y}_{\mathbf{0}} / \mathrm{D}_{=} \mathbf{0}, \mathbf{P}(\mathrm{X})\right)=\mathrm{E}(\mathrm{Y} \mathbf{1} \mid \mathrm{D}=\mathbf{1}, \mathbf{P}(\mathbf{x}))-\mathrm{E}(\mathrm{Y} 0 \mid \mathrm{D}=\mathbf{0}, \mathbf{P}(\mathbf{x}))$

Where $\mathrm{P}(\mathrm{x})$ is the propensity score computed on the covariates $(\mathrm{X})$ equation (7) is explained as; the PSM estimator is the mean difference in outcomes over the common support, appropriately weighted by the propensity score distribution of participants. According to Caliendo and Kopeinig (2008), there are steps in implementing PSM. These are estimation of propensity scores using binary model, choosing a matching algorithm, checking on common support condition, testing the matching quality.

3.5.2 Model Specification

After the proper matching is assumed the final impact evaluation model is specified as;

$\mathrm{ATT}_{\mathrm{psm}}=\mathbf{E} \mathbf{p}(\mathbf{x}) \mid \mathrm{D}_{1}=1,\{(y \mathbf{1} \mid D \mathbf{1}=\mathbf{1}, p(x))-E(y \mathbf{0} \mid D=0, p(x))\}$

Where: $\mathrm{ATT}_{\mathrm{psm}}=$ average program effect on the outcome of variable.

\section{DISCUSSION}

\section{Descripitive and Inferential analysis}

The descriptive analysis made use of tools such as mean, T-test and $\chi 2$ - test and propensity score has been employed to identify the most important factors that influence the economic contributions of Jima Ganati farmers' cooperative union to farmers. Moreover, propensity score matching, treatment effect and sensitivity 
analysis results have been presented in this section.

\begin{tabular}{lcccccc}
\hline Table 4.1 : Summary of sampling procedure, sample sizes and response rate (by sample kebeles) \\
\hline Sampled Kebele & 1 & 2 & 3 & 4 & 5 & Total \\
Number of HHs in the Kebele & 2230 & 1729 & 972 & 860 & 609 & 6400 \\
Member Farmers & 1871 & 1257 & 570 & 616 & 422 & 4736 \\
Non-member farmers & 359 & 472 & 402 & 244 & 187 & 1664 \\
Selected Samples from: & & & & & & \\
Total samples HHs in the kebele & 97 & 76 & 42 & 38 & 27 & 280 \\
Member farmers & 81 & 54 & 24 & 27 & 18 & 204 \\
Non -member farmers & 16 & 22 & 18 & 11 & 9 & 76 \\
Probability of selection: & & & & & & \\
Total samples HHs in the kebele & 34.64 & 27.14 & 15.01 & 13.57 & 9.64 & 100 \\
Member farmers & 39.51 & 26.54 & 12.03 & 13.01 & 8.91 & 100 \\
Non-member farmers & 21.57 & 28.36 & 24.15 & 14.66 & 11.26 & 100 \\
Collected Responses from: & & & & & & \\
Total sampled HHs in the kebele & 97 & 76 & 42 & 38 & 27 & 280 \\
Member farmers & 81 & 54 & 24 & 27 & 18 & 204 \\
Non-member farmers & 16 & 22 & 18 & 11 & 9 & 76 \\
Response Rates: & & & & & & \\
Total sampled HHs in the kebele & 100 & 100 & 100 & 100 & 100 & 100 \\
Member farmers & 100 & 100 & 100 & 100 & 100 & 100 \\
Non-member farmers & 100 & 100 & 100 & 100 & 100 & 100 \\
\hline
\end{tabular}

As has been shown above (Table 4.1) the total number of target population from five kebeles are 6400 out of which 4736 member farmers and 1664 non member farmers are purposively selected. The total sample households selected from these kebeles are 280 out which 204 are sample member farmers and 76 are sample non member farmers. Accordingly, responses are collected from all sample house hold respondents. Regarding responses rate worked out, 100 percent is achieved for both member and non member farmers.

Both continuous and discrete variables have been used in order to describe the sample households included in this study. As already discussed above, various variables have been used to describe both member and non member farmers. Table 4.2 shows, the mean differences between the members and non-members were significantly differ in total family size, in size of owned land, distance to agricultural extension agents office ,distance to the nearest market. On average, participant member households have larger size of land; possession of oxen, better maize crop income and family size. Compared to non-member farmers, member households have contact to extension agent and market place.

As also shown below in table 4.2, the average non-farm income of the sample members and non member farmers is about birr 1968.60 and 1609.60 respectively and it shows that high non-farm income variation among the sample households Moreover, member farmers got higher average non-farm income as compared with the non sample member farmers average non-farm income. Results of the independent sample t-test difference in mean non-farm income between the member and non-member households was found to be statistically significant at 10 percent probability level $(\mathrm{t}=1.05)$. It was confirmed during the interview with the farmers that most of the member farmers involve in petty trade and in daily labour to maximize their financial income. 
4.2. Comparison of household and farm characteristics by farmer groups

Table 4.2 : Household and farm characteristics (by farmer groups)

\begin{tabular}{lcccc}
\hline & & Mean & $\mathrm{t}$-test \\
Variables & Tember Farmer & Non member farmers & $\mathrm{t}$ & $\mathrm{p}>|\mathrm{t}|$ \\
Household head age & 42.6180 & 39.3290 & 2.3300 & 0.0210 \\
Household head sex & 0.9559 & 0.9474 & 0.3000 & 0.7640 \\
Education level of head & 4.7157 & 4.6579 & 0.1100 & 0.9120 \\
Farming Experience of head & 18.0540 & 16.3160 & 1.3200 & 0.1880 \\
None farm income & 1968.60 & 1609.60 & 1.05 & 0.29 \\
Family size & 5.0931 & 4.9079 & 0.6600 & 0.5110 \\
Distance from coop & 1.3709 & 1.1559 & 1.5000 & 0.1340 \\
Distance from market & 2.4614 & 2.4664 & -0.0200 & 0.9810 \\
Have oxen & 0.7745 & 0.6053 & 2.8600 & 0.0050 \\
Exposure to mass media & 0.7402 & 0.72368 & 0.28 & 0.781 \\
Household land size (Ha) & 3.1172 & 2.8059 & 1.2300 & 0.2190 \\
Maize land(Ha) & 1.8922 & 1.7270 & 1.0400 & 0.2990 \\
\hline
\end{tabular}

As shown above (Table 4.2), the corresponding average age of the sample farmers for the cooperative members and non-members was about 42.62 and 39.32 years respectively (Table 4.2). An independent sample ttest was conducted to compare the difference in mean age between member farmers and non member farmers sample respondents and are statistically significant at $5 \%$ probability level of significance $(\mathrm{t}=2.33)$. There is statistical significant difference between cooperative members and non-members in age and the members are more aged than the non-members.

The average family size of the members and non members that participated in the cooperative was 5.0931 and 4.6579 persons, with maximum and minimum family size of 13 and 2 persons, respectively the independent analysis shows that, the mean difference between members and non members with respect to family size is found to be statistically significant $(\mathrm{t}=0.66)$. The average oxen possession of the members and non members is 0.7745 and 0.6053 respectively. Likewise, member farmers have high exposure to mass media than non members with average of 0.7402 and 0.72368 respectively. The average educational level of the sample households in average years of schooling is 4.7157 and 4.6579 years. According to the independent sample t-test, the difference mean ttest was compared between the members and non members with respect to educational level of the household head is found to be statistically significant at $10 \%$ probability level $(\mathrm{t}=0.1100)$ This implies relatively educated member farmer do not participate in the activities of the cooperative. This is not to mean that educated member farmers have no information about the cooperative union activities as compared to less educated members, but as to the discussion held with the focus group sample respondents, they don't trust the cooperative union.

According to the independent sample t- test conducted in this study, the difference in mean house hold land size between the members and non members household heads is found to be significant at 10 percent probability level $(\mathrm{t}=1.0400)$. Therefore, from this we can conclude that the majority of the sample farmers own about half a hectare of land.

Table 4.3 indicates that the difference in mean economic income between the members and non members household heads is found to be significant at 10 percent probability level $(\mathrm{t}=1.8300)$. And also the difference in mean total cost between the members and non members household heads is found to be significant at 10 percent probability level $(\mathrm{t}=1.3490)$. Likewise, the independent sample $\mathrm{t}$ - test conducted in this study, the difference in mean house hold total maize between the members and non members household heads is found to be significant at 10 percent probability level $(\mathrm{t}=1.1200)$.

\begin{tabular}{|c|c|c|c|c|}
\hline & \multicolumn{2}{|c|}{ Mean } & \multicolumn{2}{|l|}{ t-test } \\
\hline Variable & Member & Non member & $\mathrm{t}$ & $\mathrm{p}>|\mathrm{t}|$ \\
\hline Total maize $(\mathrm{kg})$ & 95.3160 & 85.6120 & 1.1200 & 0.2630 \\
\hline Maize yield (kg/ha) & 50.2940 & 48.7700 & 0.9600 & 0.3380 \\
\hline Economic income & 30998.0000 & 25650.0000 & 1.8300 & 0.0690 \\
\hline Economic income/ha & 616.3359 & 525.9381 & 1.0230 & 0.0103 \\
\hline $\mathrm{DAP} / \mathrm{ha}(\mathrm{kg})$ & 1.2500 & 0.6500 & 1.0011 & 0.4022 \\
\hline UREA/ha (kg) & 0.6750 & 0.2500 & 2.0360 & 0.2608 \\
\hline Total cost/ha & 19012.0000 & 11880.0000 & 1.3490 & 0.0380 \\
\hline
\end{tabular}

\subsection{Estimation of propensity score matching}

The non parametric model was used to estimate propensity score matching for member farmers participant and 
non-member farmer households. As, indicated earlier, the dependent variable is continuous that indicates households' participation in the cooperative union interventions.

Table 4.4 : Propensity score

\begin{tabular}{|c|c|c|c|c|c|c|}
\hline & Coef. & Std.err & $\underline{\mathbf{Z}}$ & $\mathbf{P}>|\mathbf{z}|$ & \multicolumn{2}{|c|}{ [95\% conf. interval] } \\
\hline age & 0.0676 & 0.0340 & $1.9900^{*}$ & 0.0470 & 0.0009 & 0.1343 \\
\hline $\operatorname{sex}$ & 0.6434 & 0.6866 & 0.9400 & 0.3490 & -0.7022 & 1.9891 \\
\hline Family size & $\begin{array}{r}- \\
0.1984\end{array}$ & 0.0882 & $-2.2500 * *$ & 0.0240 & -0.3711 & -0.0256 \\
\hline HH education & $\begin{array}{r}- \\
0.1016\end{array}$ & 0.0449 & $-2.2600 * *$ & 0.0240 & -0.1896 & -0.0136 \\
\hline Own land & 0.0454 & 0.1812 & 0.2500 & 0.8020 & -0.3097 & 0.4005 \\
\hline Rental land & $\begin{array}{r}- \\
0.6860\end{array}$ & 0.4723 & -1.4500 & 0.1460 & -1.6118 & 0.2398 \\
\hline Share cropped & $\begin{array}{r}- \\
0.6900\end{array}$ & 0.2302 & $-3.0000 * * *$ & 0.0030 & -1.1412 & -0.2388 \\
\hline Farming experience & $\begin{array}{r}- \\
0.0698\end{array}$ & 0.0343 & $-2.0300 * *$ & 0.0420 & -0.1371 & -0.0026 \\
\hline Maize land & 0.2734 & 0.2506 & 1.0900 & 0.2750 & -0.2177 & 0.7644 \\
\hline livestock & 0.0000 & 0.0000 & 1.2300 & 0.2190 & 0.0000 & 0.0001 \\
\hline Distance from coop & 0.3546 & 0.3197 & 1.1100 & 0.2670 & -0.2719 & 0.9811 \\
\hline Distance from market & $\begin{array}{r}-\overline{-} \\
0.2628\end{array}$ & 0.1296 & $-2.0300 * *$ & 0.0430 & -0.5169 & -0.0087 \\
\hline Distance from ext office & $\begin{array}{r}- \\
0.0255\end{array}$ & 0.3328 & -0.0800 & 0.9390 & -0.6778 & 0.6268 \\
\hline Livestock income & 0.0000 & 0.0000 & -1.0100 & 0.3130 & -0.0001 & 0.0000 \\
\hline Non farm income & 0.0000 & 0.0001 & 0.5400 & 0.5920 & -0.0001 & 0.0002 \\
\hline media & 0.2216 & 0.3442 & 0.6400 & 0.5200 & -0.4530 & 0.8961 \\
\hline
\end{tabular}

Looking into the estimated coefficients (Table 4.4), the results indicate that the economic contribution of the cooperative union is significantly influenced by four explanatory variables and two dummy variables. Distance from market, family size, farming experience, education level, and share cropped farming is significant variables affect the program intervention. Households nearer to market and office of the extension agents are more likely to be included in the program than those living far from the market and extension office. Similarly, households who do have largest family size are less likely to participate in the cooperative union interventions than households having less family sizes. Besides, households who have much experience in farming are less likely to participate in cooperative intervention.

Graph 1 : Histogram of Pscore with common (off) support regions

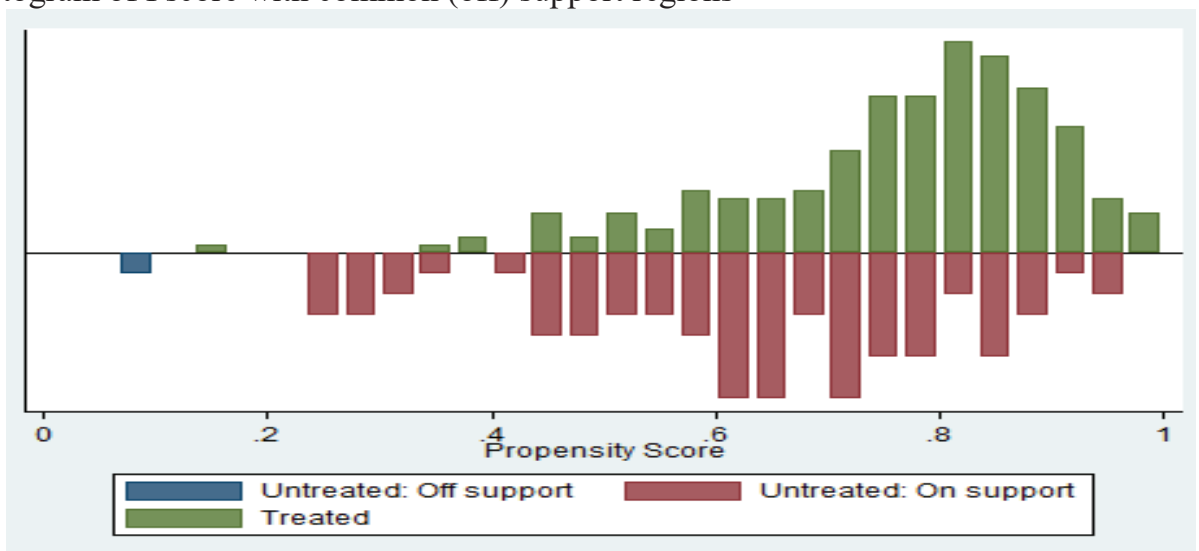


Table 4.5. Distribution of estimated propensity scores

\begin{tabular}{|lcccll|}
\hline Group & Obs & Mean & STD & Min & Max \\
\hline Total households & 280 & 255.17 & 152.18 & 11 & 534 \\
\hline Treatment households & 204 & 1.61 & 0.81 & 2.14 & 2.43 \\
\hline Control households & 76 & 0.33 & 0.21 & 0.01 & 0.74 \\
\hline
\end{tabular}

Source: Own survey result

Graph 2 below portrays the distribution of the household with respect to the estimated propensity scores after matching. In case of treatment households, most of them are found in partly the middle and partly in the right side of the distribution. On the other hand, most of the control households are partly found in the center and partly in the left side of the distribution.

Graph 2: Kernel density of propensity scores after matching

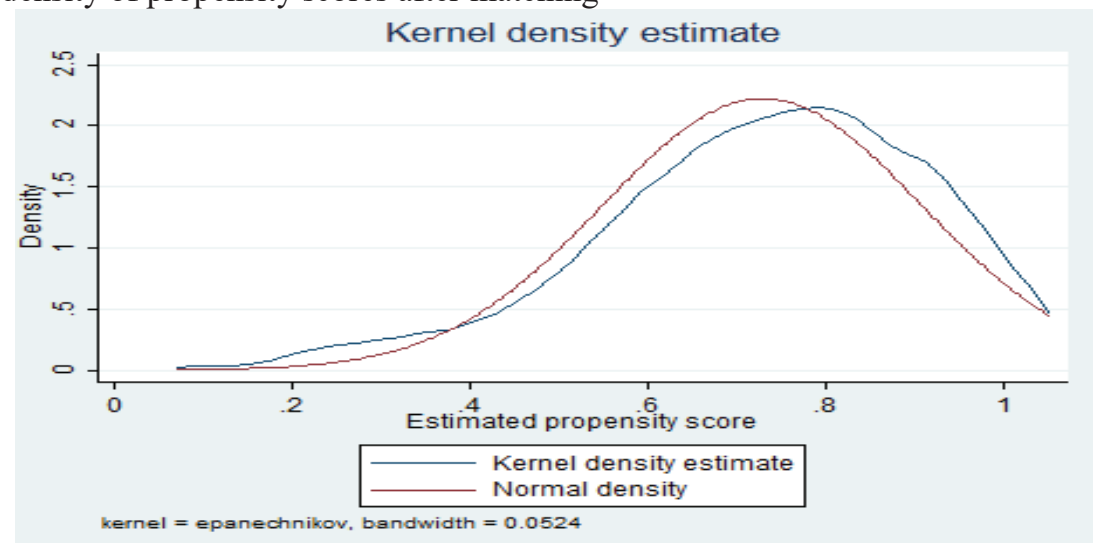

\subsubsection{Testing the Balance of Propensity Score and Covariates}

After choosing the best performing matching algorithm the next task is to check the balancing of propensity score and covariate using different procedures by applying the selected matching algorithm(in our case kernel matching). The mean standardized bias before and after matching are shown in the fifth columns of table 4.6, while column six reports the total bias reduction obtained by the matching procedure. In the present matching models, the standardized difference before matching is in the range of 16 percent and 21.7 percent in absolute value. After matching, the remaining standardized difference for almost all covariates lie between 8.8 percent and 11.4 percent, which is below the critical level of 20 percent suggested by Rosenbaum and Rubin (1985). In all cases, it is evident that sample differences in the unmatched data significantly exceed those in the samples of matched cases.

Table 4.6: Propensity score and covariate after matching

\begin{tabular}{|c|c|c|c|c|c|c|}
\hline & & & & & \multicolumn{2}{l|}{} \\
Variable & Coef. & Std.err & $\mathbf{z}$ & \multicolumn{2}{|c|}{$\mathbf{P}>\mathbf{z} \mid$} & \multicolumn{2}{c|}{$[\mathbf{9 5 \%}$ conf.interval] } \\
\hline constant & -0.1805 & 1.1705 & -0.1500 & 0.8770 & -2.4746 & 2.1136 \\
\hline age & 0.0676 & 0.0340 & 1.9900 & 0.0470 & 0.0009 & 0.1343 \\
\hline sex & 0.6434 & 0.6866 & 0.9400 & 0.3490 & -0.7022 & 1.9891 \\
\hline famsize & -0.1984 & 0.0882 & -2.2500 & 0.0240 & -0.3711 & -0.0256 \\
\hline hheduc & -0.1016 & 0.0449 & -2.2600 & 0.0240 & -0.1896 & -0.0136 \\
\hline ownland & 0.0454 & 0.1812 & 0.2500 & 0.8020 & -0.3097 & 0.4005 \\
\hline renland & -0.6860 & 0.4723 & -1.4500 & 0.1460 & -1.6118 & 0.2398 \\
\hline shcrop & -0.6900 & 0.2302 & -3.0000 & 0.0030 & -1.1412 & -0.2388 \\
\hline expfarm & -0.0698 & 0.0343 & -2.0300 & 0.0420 & -0.1371 & -0.0026 \\
\hline maizels & 0.2734 & 0.2506 & 1.0900 & 0.2750 & -0.2177 & 0.7644 \\
\hline vlstock & 0.0000 & 0.0000 & 1.2300 & 0.2190 & 0.0000 & 0.0001 \\
\hline distcoop & 0.3546 & 0.3197 & 1.1100 & 0.2670 & -0.2719 & 0.9811 \\
\hline distmkt & -0.2628 & 0.1296 & -2.0300 & 0.0430 & -0.5169 & -0.0087 \\
\hline distext & -0.0255 & 0.3328 & -0.0800 & 0.9390 & -0.6778 & 0.6268 \\
\hline lsinc & 0.0000 & 0.0000 & -1.0100 & 0.3130 & -0.0001 & 0.0000 \\
\hline nfinc & 0.0000 & 0.0001 & 0.5400 & 0.5920 & -0.0001 & 0.0002 \\
\hline media & 0.2216 & 0.3442 & 0.6400 & 0.5200 & -0.4530 & 0.8961 \\
\hline
\end{tabular}




\subsubsection{Impact of estimate on household income}

Table 4.9 shows that the impact of estimate on yields are significantly different from zero for total household income from maize production, livestock and non-farm activities. The explanation is the absence of better market in paying better price for quality maize product. Table 4.9: ATT for total income.

\begin{tabular}{|l|c|c|c|c|c|}
\hline Algorithms & member & nonmember & ATT & Std. err & t-value \\
\hline attnd & 203 & 57 & 0.1330 & 0.1600 & 0.8310 \\
\hline atts & 202 & 76 & 0.1060 & 0.0970 & 1.0980 \\
\hline attr0.01 & 167 & 63 & 0.0460 & 0.1330 & 0.3450 \\
\hline attr0.005 & 126 & 61 & 0.0150 & 0.1430 & 0.1050 \\
\hline attk & 203 & 75 & 0.0750 & 0.1120 & 0.6670 \\
\hline
\end{tabular}

Imoisili, (2001) classifies the role of cooperatives into six major areas as: empowerment of men and women, gender equality, pro-poor growth, global benefit from global competition, an enabling environment for pro-poor policies and market (under which cooperatives' economic contributions is falling), and special international support. Cooperatives union can help farmers move out of poverty, and cooperatives are one form that these groups can take and the cooperatives are often the main channel through which smallholders can access fairtrade Imoisili, (2001). In line with the country's agricultural policy, the table depicted above shows that participation in the farmers' cooperative activities has increased overall income of the households ranging between 1.5 percent for ATT estimation with the stratification matching method ( attr 0.005 ) to 13.3 percent for ATT estimation with kernel density matching method(attnd).

\section{Conclusion}

The descriptive statistics and propensity score matching model were also used for analyzing the data. t-test was used to compare the mean values of the continuous explanatory variables and examine the existence of statistically significant differences between the cooperative members and non-member farmers. The T-test showed significant difference in the age of the household heads, farming experience, land holding and yield obtained from maize between the two groups at less $10 \%$ probability level. Discrete variables were also compared using Chi-square test to see if there is statistically significant difference between the two. The Chisquare test also revealed that the discrete variables showed significant differences between the two groups at less than $10 \%$ probability level. More specifically, these variables include, family size, cooperative price for maize, farm size, yield of maize, distance of the cooperative from the farmer's house and distance of the district (main) market from the farmer's house were found to be significantly related to the farmers' marketing of maize through the cooperative union.

In the study area the impact of Jima Ganati cooperative union intervention in economic activities has been assessed using cross sectional data collected for the same purpose. The primary data for this study were collected from 280 households from both member and non-member farmers households found in Jima Ganati district using a structured questionnaire. Hence, the study has applied a propensity score matching technique which has become the most widely applied non-experimental tool for impact evaluation of economic programs. It is used to extract comparable pair of treatment-comparison households in a non-random program setup and in the absence of baseline data. Moreover, it can adjust for (but not totally solve the problem of) selection bias and in estimating the counterfactual effects.

As expected, the farmers' (members and non members) income from maize crop through the cooperative union intervention was determined by a combination of factors and is significantly influenced by six explanatory variables. These variables are: size of farm land, oxen possession, family size, distance to cooperative office, distance to market, and distance to agricultural extension office are the significant variables which affect the crop income of the household through the cooperative union intervention.

Households nearer to market and agricultural extension office are more likely were included in the cooperative intervention than household living far from the market and office. Similarly, households who have large family size are less likely to have income from maize crop than those who do have small family size. Besides, size of owned land and oxen has a strong and positive effect on household crop income through cooperative intervention.

Finding a reliable estimate of the project impact necessitates controlling for all such confounding factors adequately. In doing so, propensity score matching has resulted in member participant households matched with non member participant households after discarding households whose values were out of common support region. The resulting matches passed on many process of matching quality tests such as t-test, reduction in standard bias and chi-square test.

The impact estimation results then indicated that there are significant differences in development outcomes between treatment and comparison households, which could be attributable to the cooperative union interventions. The effect of the intervention on total household income is higher for the member households which are statistically significant. Treated households gained significantly large proportion of income from 
maize crop compared to the comparison ones. Moreover, cooperative union involvement in various economic activities become an important change observed and is a substitute of the public sector role in the long run. The result of Rosenbaum bounding procedure to check the hidden bias due to unobservable selection showed that all estimated ATTs for all significant outcome variables are insensitive which clearly indicated its robustness.

\section{Recommendations}

Based on the study results and empirical findings reported in this thesis, the following recommendations are arrived at for improving the economic contributions of Jima Ganati farmers' cooperative union to farmers. During the informal survey, farmers were complaining to the price set per quintal of agricultural inputs was not as they expected and was not fair price compared to the production cost they incurred. Besides, the farmers were complaining to the weak performance of cooperative union in output marketing as the farmers had interest to supply their output.

Thus, there is a need for complete interventions in the input and output marketing towards managing high price fluctuations and developing institutional mechanisms that can help minimize the production costs and strategically scheduling to purchase the products supplied by the farmers to help protect the farmers from output price distortions and to play a great role in market stabilization. In this regard, strengthening the linkage between cooperative union and the respective primary cooperatives are very important. The concerned bodies should create awareness about a cooperative and the agricultural development it can bring to the area in the longrun. Continuous education and enlightenment of the member farmers will have a positive impact on their attitudes towards the cooperatives as it is among the internationally accepted cooperative principles. However, survey result shows that, lack of appropriate training and education especially to board of directors is one of the very important problems identified by the sample house hold members. Therefore, as member farmers are the poles and nucleus of the cooperative, due attention should be given by the governmental and nongovernmental organizations for members' education and awareness creation.

Hence, it is suggested that more attention is to be given to the human resource development of the cooperative union management bodies through short term and long term training programs to able to sustain the cooperative union. Moreover, professional management is becoming crucial issue for the cooperative union in order to run viable and profitable business that can improve and boost the income and productivity of the farmers.

\section{REFERENCES}

(1) Acharya, S.S. (2004). "Agricultural Marketing and Credit Status; Issues and Reform Agenda." National Center for Agricultural Economics and Research. New Delhi.

(2) Alema (2008). Analysis of the Role of Cooperatives in Agricultural Input and Output Marketing in Southern Zone of Tigray, Ethiopia

(3) Bedasa, T. (2018). Cooperatives for Staple Crop Marketing: Evidence from Ethiopia. International Food Policy Research Institute. Washington.

(4) Bernard, T. et al (2010). Cooperatives for Staple Crop Marketing: Evidence from Ethiopia. International Food Policy Research Institute. Washington.

(5) Birchall, J. (2003). Rediscovering the cooperative advantage: Poverty reduction through self help. International Labor Office, Cooperative Branch. Geneva.

(6) Caliendo, M., and Kopeinig, S., (2008). Some practical guidance for the implementation of propensity score matching. IZA Discussion Paper No. 1588, University of Cologne.

(7) Chukwu, S.K., (2006). Economics of the Cooperative Business Enterprise. Marburg, Germany.

(8) Dereje, A., (2015). From farmer to market and market to farmer: Characterizing smallholder commercialization in Ethiopia. Paper submitted for ESSP Policy Conference on Bridging, Balancing, and Scaling up: Advancing the rural growth agenda in Ethiopia. Addis Ababa, Ethiopia.

(9) Duguma, A., Feyisa, T.,(2017) . Performance of farmers' Cooperative Union and Promotion: the case Alaltu Farmers' Cooperative Union.

(10) Ethan L. (2009) "Risk Management in the Cooperative Contract", American Journal of Agricultural Economics. 91, No. 5 (2009): 1211-1217.

(11) FAO, (2015): Agricultural cooperatives: paving the way for food security and rural development, Available from: http://www.fao.org/docrep/016/ap431e/ap431e.pdf.

(12) Gujarati, D.N., (1999). Essentials of Econometrics. 2nd edition. Mc-Graw-Hill Companies

(13) MoFED (Ministry of Finance and Economic Development), (2017). Building on progress: A Plan for Accelerated and Sustained Development to End Poverty (PASDEP). Addis Ababa, Ethiopia.

(14) Taye, W., (2014). Impact assessment of urban agriculture research and development in Ethiopia, Adama.

(15) Rosenbaum, P.R. and Rubin, D.B., 1983. The central role of the propensity score in observational studies for causal effects. Biometrika, 70(1): 41-55. 